\title{
The effect of type and concentration of acid on the characteristics of gelatine from bones of milkfish (Chanos chanos)
}

\author{
*Winarti, S., Sarofa, U. and Prihardi, M.Y.R. \\ Food Technology Program, Engineering Faculty, University of Pembangunan Nasional “Veteran” Jawa \\ Timur, Jalan Raya Rungkut Madya, Surabaya, Indonesia, 60294.
}

\begin{abstract}
Article history:
Received: 1 December 2020

Received in revised form: 23 January 2021

Accepted: 13 April 2021

Available Online: 31 August 2021
\end{abstract}

\section{Keywords:}

Gelatine,

Bone of milkfish,

Citric acid,

Acetic acid

DOI:

https://doi.org/10.26656/fr.2017.5(4).690

\begin{abstract}
Gelatin is derived from the hydrolysis of the animal collagen contained in the bones and skin. Milkfish bones have the potential to be used as raw materials for gelatine production because it is estimated to be $15-20 \%$ of the total body weight of the fish. The extraction of gelatine from fish bones is a solution in utilizing the waste of the fish processing industry. Hydrolysis or soaking in an acidic solution against collagen is aimed to eliminate the salt of calcium and other minerals in the cartilage. This research was conducted to determine the influence of acid types and concentration on the milkfish bones gelatine production. This study used a completely randomized factorial design with two factors. The first factor was the type of acid (citric acid, acetic acid, and a mixture of citric and acetic acids), while the second factor was the concentration of acid (5\%,9\%, and 13\%). The data obtained were analysed using Analysis of Variance (ANOVA) and Duncan Multiple Range Test (DMRT) Advanced test. The results showed that the type and concentration of acid affected the yield, gel strength, viscosity, melting point, and gelling point. The best treatment in this study was extraction using a $9 \%$ concentration of citric acid to produce gelatine with a yield of $10.48 \%$, gel strength $283.1 \mathrm{~g}$ bloom, viscosity $4.35 \mathrm{cP}$, melting point $60.1{ }^{\circ} \mathrm{C}$, gel point $16.9^{\circ} \mathrm{C}$. Identification of gelatine functional groups was carried out on gelatine from the best treatment using FT-IR Spectrophotometer. From the results of FT-IR spectra analysis, it is known that the functional groups present in the sample are $\mathrm{OH}, \mathrm{C}-\mathrm{O}, \mathrm{N}-\mathrm{H}, \mathrm{C}-\mathrm{H}, \mathrm{C}-\mathrm{N}, \mathrm{C}=\mathrm{O}$ which are the main functional groups of gelatine. This study showed that the type and concentration of acid affected the characteristics of milkfish bone gelatine.
\end{abstract}

\section{Introduction}

Gelatine is a protein food ingredient obtained by the thermal denaturation of collagen. It becomes a main functional biopolymer due to its ability to form heatreversible gels with water (Fernando et al., 2007). It is widely utilized in the food industry for increasing the viscosity of aqueous systems, specifically in dessert formulations (Ahmed et al., 2005). Gelatine is derived from the hydrolysis of the animal collagen contained in the bones and skin (Balaji and Tanaji, 2017). The production of gelatine generally uses collagen obtained from the bones and skin of cows and pigs. The use of this material turned out to be a problem for its users. The use of bones and skin of cows will be a problem for the Hindus, while the use of material from pigs will be a problem for the Muslims and Jews. Based on these problems, it is necessary to look for other alternatives for other raw materials in the production of gelatine.
Milkfish bones are very potential to be used as raw materials for gelatine production because the bones are estimated for $15-20 \%$ of the total body weight of fish (Marion et al., 2010). The extraction of gelatine from fish bones is a solution in utilizing the waste of the fish processing industry. The bones dissipated as waste from the milkfish processing industry in Sidoarjo and the surrounding areas, recorded every day, was up to $15 \mathrm{~kg}$ or 5 tons per year (Hijriani, et al., 2015). Since the bones have not been utilized optimally, it is very potential as the raw material for gelatine production.

Research on the isolation of collagen yields from several fish species and other body parts have been carried. Nile perch fish skin collagen extraction (young age) obtained yields of $63.1 \%$ and $58.7 \%$ in adult age; in chub mackerel, bullhead shark, and Japanese snapper obtained collagen yields respectively: $49.8 \% ; 50.1 \%$; and $51.4 \%$ (Jongjareonrak et al., 2005). In cod and Baltic cod 
are found collagen respectively: $71.2 \%$ and $74.4 \%$ (Sadowska et al., 2003). While from cuttlefish skin, obtained Acid Soluble Collagen (ASC) by $2 \%$ and Pepsin Soluble Collagen (PSC) by 35\% (Nagai et al., 2001). Differences in species, habitats and treatment in the extraction process are very influential on the yield, character, and molecular composition of collagen. Research on collagen from fish species domestic is still very rarely done, so the related data is insufficient.

The processing method is a crucial point in making gelatine. Based on the processing method, gelatine is divided into two types, namely, type A and type B. Type A is made in acidic conditions, while type B is made in alkaline conditions. Acid is able to convert triple helix collagen fibre into single chains, while alkaline soaking solutions are only able to produce double chains. This causes the amount of collagen that can be hydrolysed by acidic solutions to be more than alkaline solutions, therefore immersion in alkaline solutions requires a longer time to hydrolyse collagen (Schrieber and Gareis, 2007; Gumilar and Pramana, 2018). Economically, the process of making gelatine using the acid hydrolysis method is more effective than the alkaline hydrolysis method (Perwitasari, 2008). Extraction of milkfish bone gelatine uses food-grade acids so that later if the residual acid left from the gelatine is not harmful to consumers. Types of organic acids that can be used are acetic acid, citric acid, fumaric acid, ascorbic acid, malic acid, succinic acid, tartaric acid, and other safe acids (Pelu et al., 1998).

Generally, the principal production process of gelatine was divided into three main phases: the preparation of the raw materials stage, the collagen conversion to become the gelatine stage, and the purification using filtration and drying stage. An important process is carried out on fish bones before they are processed into gelatine, namely the liming and degreasing processes. The degreasing process aims to remove fats that are still present in the skin and bone tissue by the cooking process, while liming aims to dissolve non-collagen components and to soften bones, besides that it also aims to damage or break certain chemical bonds that are still present in collagen and to remove or reduce other unwanted material, such as other proteins and carbohydrates. During the liming process, fat is converted into dissolved alkaline soaps (Atma and Ramdhani, 2017; Pertiwi et al., 2018).

The gelatine solution subsequently was purified by filtering and drying it up to the final product until the water content reached 9-16\% (Gelatin Manufacturers Institute of America, 2012). The purpose of the soaking process using an acidic solution was to perform the demineralization or eliminating the salt of calcium and other minerals existing in the cartilage. The acids used in the extraction of this gelatine were citric acid, acetic acid, and a mixture of citric and acetic acids with various concentrations. The use of a mixture of citric acid and acetic acid is expected to produce better yields and characteristics of gelatine than the use of a single acid. This research was conducted to determine the influence of acid types (citric acid, acetic acid, and a mixture of citric and acetic acids), and concentration (5\%, $\%$, and $13 \%$ ) on the milkfish bones gelatine production.

\section{Materials and methods}

\subsection{Materials and equipment}

The raw material used in this research was the milkfish bone collected from the base of the boneless milkfish industry at Kalanganyar Traditional market, Sedati District, Sidoarjo Regency, East Java Province, Indonesia. The chemicals used were acetic acid (Sigma), citric acid (Sigma), distilled water, $\mathrm{H}_{2} \mathrm{SO}_{4}, \mathrm{Na}_{2} \mathrm{SO}_{4}-\mathrm{HgO}$, $\mathrm{NaOH}-\mathrm{Na}_{2} \mathrm{~S}_{2} \mathrm{O}_{3}$, boric acid, Kjeldahl tablets, and $\mathrm{KBr}$. The instruments used in this research were a cabinet dryer, digital scales, a thermometer, a gas stove, a knife, a water bath, plastic container tools, and glassware. The analytical equipment used were analytical balances, ovens, desiccators, a set of LFRA Texture Analyzer 4500 (serial number M05-370), a set of Viscometer models RVT, and a Fourier Transform Infrared (FTIR) spectrophotometer Shimadzu Perkin Elmer, hand press Shimadzu, computer operating system Microsoft Windows XP Professional.

This study used a completely randomized factorial design with two factors. The first factor was the type of acid (citric acid, acetic acid, and a mixture of citric and acetic acids), while the second factor was the concentration of acid (5\%, 9\%, and 13\%). The data obtained were analysed using Analysis of Variance (ANOVA) and Duncan's Multiple Range Test (DMRT) advanced test.

\subsection{Gelatine production}

The milkfish bones were detached and washed with running water to remove the rest of the flesh attached to the bones. The clean bones were then soaked in water with temperatures between $70-80^{\circ} \mathrm{C}$ for two hrs. The bones were soaked in acid solutions (citric acid, acetic acid, and a mixture of them) with various concentrations $(5 \%(\mathrm{v} / \mathrm{v}), 9 \%(\mathrm{v} / \mathrm{v})$, and $13 \%(\mathrm{v} / \mathrm{v}))$ for $48 \mathrm{hrs}$, where the ratio of bones and acid was $1: 3 \mathrm{~b} / \mathrm{v}$ (the fish bones were soaked in an acid solution with a volume of 3 times the weight of the fish bones). Subsequently, the bones were washed with flowing water to remove the acid residue until the $\mathrm{pH}$ value was between 5 and 6 . The acquired soft bones (ossein) were extracted using distilled water at 
$60-65^{\circ} \mathrm{C}$ for six hours. The ratio of ossein and distilled water was $1: 3 \mathrm{~b} / \mathrm{v}$. The obtained gelatine solution was filtered using a filter cloth and then was dried in the cabinet dryer at a temperature of $50^{\circ} \mathrm{C}$ for $24 \mathrm{hrs}$. The dry gelatine obtained was analysed for its characteristics including the yield, gel strength, viscosity, melting point, and gelling point. Identification of gelatine functional groups was carried out on gelatine from the best treatment using FT-IR Spectrophotometer.

\subsection{Determination of gel strength}

(British Standard Method 757, 1975), gelatine solution with a concentration of $6 \%$ was prepared ( $6 \mathrm{~g}$ of gelatine plus $100 \mathrm{~mL}$ aquadest). The gelatine solution was stirred using a magnetic stirrer until it was homogeneous then heated to a temperature of $600^{\circ} \mathrm{C}$ for 15 minutes. Gelatine solution was then incubated at $100^{\circ}$ $\mathrm{C}$ for $17 \mathrm{hrs}$. Gelatine gel strength was measured using the LFRA Texture Analyzer 4500 (serial number M05370 ) at a probe speed of $4 \mathrm{~mm} / \mathrm{second}$, a distance of 60 $\mathrm{mm}$, a speed of $12 \mathrm{~mm} /$ minute graph paper and a probe diameter of $12.7 \mathrm{~mm}$. The value of gel strength is expressed in units of $\mathrm{g}$ bloom.

\subsection{Gelatine viscosity measurement}

(British Standard Method 757, 1975), gelatine solution with a concentration of $6 \%$ is prepared $(6 \mathrm{~g}$ of gelatine plus $100 \mathrm{~mL}$ aquadest). The viscosity of the gelatine solution was measured using a brookfield viscometer. Measurements are made at $600^{\circ} \mathrm{C}$ with a shear rate of $60 \mathrm{rpm}$ using a spindle 1 . The measurement results are multiplied by the conversion factor, where for spindle 1 the conversion factor is 1 . The viscosity value is expressed in units of centipoise (cP).

\subsection{Identification of gelatine functional groups by FTIR}

A fine sample of $0.2 \mathrm{~g}$ was mixed with fine $\mathrm{KBr} 0.1$ g. The pellet mould was prepared and the base and the tablet frame was washed with chloroform. The mixture is placed into the pellet mould set. To minimize moisture content a vacuum pump was connected. The vacuum pump was turned on for 5 mins. The mould was placed in the hydraulic pump, then pressurized up to the 80 mark. The vacuum pump was turned, then the pressure in the mould was reduced by opening the air tap. $\mathrm{KBr}$ pellets that have been formed were removed and placed on the tablet holder. The measurements were read with the FT-IR.

\section{Results and discussion}

The analysis of gelatine from milkfish bones conducted in this study included the yield, gel strength, viscosity, melting point, gelling point, and analysis of the gelatine function group using FT-IR (Spectrophotometer Fourier Transform Infra-Red) for the best treatment. The characteristics of gelatine from the milkfish bones can be seen in Table 1.

\subsection{Yield of gelatine}

Based on the analysis of variance, it is known that there was an interaction between the acid type and acid concentrations, and each treatment showed a remarkable effect on the gelatine yield of the milkfish bones. It is known that there was an increase in the yield of milkfish bone gelatine in the acetic acid treatment and the mixture of citric and acetic acid treatments with increasing concentrations. This is because the high acid concentration can break the triple-helix chain into single chains so that more water-soluble gelatine during the extraction process. However, in the citric acid treatment, the yield increased at a concentration of $9 \%$ and decreased at a concentration of $13 \%$. The higher the concentration of acid which is able to open a larger collagen structure and cause the collagen structure to expand and open. The higher the opening rate of the collagen structure causes the amount of extracted collagen to increase (Hidayat et al., 2016). A large amount of collagen is influenced by the amount of acid that can dissolve calcium salts and causes the collagen in ossein to also increase as well as the increase in the amount of gelatine produced after the extraction process, due to hydrolysis by $\mathrm{H}^{+}$ions from the triple helical chain into a single water-soluble chain. Excess acid concentration causes further hydrolysis so that some of the gelatine is also degraded and causes a decrease in the amount of gelatine (Setiawati, 2009). The higher the acid concentration, the more acid cations are trapped in the ossein, so that the measured $\mathrm{pH}$ is getting lower (acid)

Table 1. Characteristics of gelatine from the milkfish bones

\begin{tabular}{lccccccccc}
\hline \multirow{2}{*}{ Parameter } & \multicolumn{3}{c}{ Citric Acid } & \multicolumn{3}{c}{ Acetic Acid } & \multicolumn{3}{c}{ Mixed } \\
\cline { 2 - 10 } & $5 \%$ & $9 \%$ & $13 \%$ & $5 \%$ & $9 \%$ & $13 \%$ & $5 \%$ & $9 \%$ & $13 \%$ \\
\hline Yield (\%) & $4.33^{\mathrm{e}}$ & $10.48^{\mathrm{a}}$ & $9.10^{\mathrm{b}}$ & $2.48^{\mathrm{f}}$ & $3.65^{\mathrm{e}}$ & $4.0^{\mathrm{e}}$ & $4.55^{\mathrm{e}}$ & $6.15^{\mathrm{d}}$ & $7.95^{\mathrm{c}}$ \\
Gel strength (g bloom) & $239.5^{\mathrm{b}}$ & $283.1^{\mathrm{a}}$ & $270.3^{\mathrm{a}}$ & $170.8^{\mathrm{e}}$ & $206.9^{\mathrm{c}}$ & $263.2^{\mathrm{ab}}$ & $186.0^{\mathrm{d}}$ & $241.6^{\mathrm{b}}$ & $278.5^{\mathrm{a}}$ \\
Viscosity $(\mathrm{cP})$ & $2.5^{\mathrm{e}}$ & $4.35^{\mathrm{a}}$ & $3.3^{\mathrm{c}}$ & $1.9^{\mathrm{f}}$ & $2.5^{\mathrm{e}}$ & $4.0^{\mathrm{b}}$ & $2.8^{\mathrm{d}}$ & $3.4^{\mathrm{c}}$ & $4.25^{\mathrm{a}}$ \\
Melting Point $\left({ }^{\circ} \mathrm{C}\right)$ & $53.4^{\mathrm{d}}$ & $60.1^{\mathrm{a}}$ & $58.9^{\mathrm{b}}$ & $45.3^{\mathrm{h}}$ & $50.3^{\mathrm{f}}$ & $51.3^{\mathrm{e}}$ & $47.7^{\mathrm{g}}$ & $52.1^{\mathrm{e}}$ & $57.6^{\mathrm{c}}$ \\
Gelling Point $\left({ }^{\circ} \mathrm{C}\right)$ & $16.1^{\mathrm{ab}}$ & $16.9^{\mathrm{a}}$ & $16.7^{\mathrm{a}}$ & $12.2^{\mathrm{d}}$ & $14.0^{\mathrm{c}}$ & $14.9^{\mathrm{b}}$ & $13.6^{\mathrm{c}}$ & $15.4^{\mathrm{b}}$ & $16.6^{\mathrm{a}}$ \\
\hline
\end{tabular}

Values with different superscript within the column are significantly different 
and collagen hydrolysis will continue in the process of breaking down the collagen polymer (Hidayat et al., 2016).

\subsection{Gel strength}

Based on the analysis of variance, there was an interaction between acid type and acid concentration on the gel strength characteristic. It is known that there was an increase in the yield of gel strength in acetic acid treatment and treatment of a mixture of citric acid and acetic acid with increasing concentration, but in citric acid treatment, the gel strength increased to a concentration of $9 \%$ and decreased at a concentration of $13 \%$. Excess acid concentration causes further hydrolysis so that some of the gelatine is also degraded and causes a decrease in the amount of gelatine (Setiawati, 2009). According to (Sompie et al., 2014), the gel strength was decreased because of the occurrence of the termination process of amino acid polymer chains with the increase of acid concentrations. It split the bond between molecules of the collagen compound polymer into a very short monomer chain and suffered damage. It also caused the gel formation process to be reduced.

\subsection{Viscosity}

Based on the analysis of variance, there was an interaction between acid type and acid concentration on the viscosity characteristic. Each treatment also proffered a noticeable effect on the viscosity of gelatine from the milkfish bones. The viscosity of each treatment was increasing along with the increase of acid concentrations. The resulting chain of gelatine amino acids remained long that made the viscosity value increased. This viscosity value is directly proportional to the value of the gel strength. According to (Trilaksani et al., 2012), where the great value of viscosity was caused by the conversion of collagen into gelatine that occurred optimally. The amino/oligopeptide chain was formed sufficiently long, and its viscosity became higher. However, in the citric acid treatment, the viscosity increased at a concentration of $9 \%$ and decreased at a concentration of $13 \%$. This viscosity value was directly proportional to the value of the resulting gel strength. It was due to the further hydrolysis that caused the resulting gelatine amino acid chain to be severed and became shorter so that the viscosity decreased. According to (Huda et al., 2013), the amino acid chain in gelatine would be disrupted along with an increase in the concentration of solvent characterized by the decrease of viscosity value.

\subsection{Melting point}

A melting point of gelatine is the temperature when the gelatine melts when heated slowly. Based on the analysis of variance, there was an interaction between acid type and acid concentration on the melting point of gelatine. Each treatment presented a noticeable effect on the melting point of gelatine from the milkfish bones. The melting point of gelatine on the acetic acid and mixed acid treatment increased with the increase of concentration. The melting point increased at a concentration of $9 \%$ and decreased at a concentration of $13 \%$ on the citric acid treatment. Gelatine, with a slight amount of hydrogen bonds, would form a gel at a lower temperature. The bond between the gelatine molecules was weak that made the gelatine quickly melt. Conversely, plenty of hydrogen bonds would make the gelatine formed a gel faster. It made the bond between the gelatine molecules stronger. Therefore, when the temperature rose, the cross-connect bonds would lose slowly and melt at higher temperatures (Fernando et al., 2007; Zulkifli et al., 2014). The relationship of melting point with the quality of gelatine prevailed in the composition of the acid sequence, especially the hydroxyproline amino acids, and the molecular weight of gelatine produced.

\subsection{Gelling point}

Based on the analysis of variance, there was an interaction between acid type and acid concentration on the gelling point characteristic. Each treatment showed a noticeable effect on the gelling point of the gelatine from milkfish bone (Table 1). The gelling point of gelatine on the acetic acid and mixed acid treatment increased along with the increase of concentration. Despite that, in the treatment of citric acid, the gelling point increased at a concentration of $9 \%$ and decreased at a concentration of $13 \%$. The value of the gelling point was directly proportional to the melting point and value. The gelling point was affected by the amount of hydroxyproline amino acids and protein concentration. According to (Balaji and Tanaji, 2017), high protein concentrations contained high hydroxyproline. The amount of hydroxypropyl contained in gelatine was directly equivalent to the number of hydrogen bonds that might be formed when gelatine was dispersed in water. According to Fernando et al. (2007), the gelling point and melting point of gelatine were affected by the concentration of gelatine in solution, $\mathrm{pH}$, and the molecular weight of gelatine.

\subsection{Functional group analysis of milkfish bone gelatine}

The analysis of the functional group of fishbone gelatine was performed at the best treatment, which was the treatment of citric acid with a concentration of $9 \%$. The analysis of the functional group of gelatine was completed using the FTIR, where the results were obtained in the form of the absorption graph of the 
functional group of gelatine. The test result of the functional group of gelatine was shown in Figure 1. The results shown on the curve were divided into four absorption areas, namely Amide A, Amide I, Amide II, and Amide III, which were the absorption areas of the typical functional group of gelatine. The uptake area of amide $\mathrm{A}$, shown in $\mu=3580-3650 \mathrm{~cm}^{-1}$, was an absorption area of the group $\mathrm{O}-\mathrm{H}$ and strain $-\mathrm{N}-\mathrm{H}-$, as well as the strain $-\mathrm{CH}_{2}-$ at about $2930 \mathrm{~cm}^{-1}$. The measuring result of the gelatine showed a strong uptake of the $3473.19 \mathrm{~cm}^{-1}$ wavelength, which were the O-H (hydrogen bond alcohol) and $\mathrm{N}-\mathrm{H}$ (amide) clusters. Moreover, the strong uptakes of the 2925.18 and 2854.20 $\mathrm{cm}^{-1}$ wavelengths belonged to the C-H cluster (alkane). Thus, the tested milkfish bone gelatine had been shown to have an $\mathrm{O}-\mathrm{H}$ cluster, N-H strain, and C-H strain. The next typical gelatine cluster was amide I. The presence of a double bond strain of carbonyl group, $=\mathrm{C}=\mathrm{O}$, and strain - CN - caused absorption of uptake at frequencies $1660-1644 \mathrm{~cm}^{-1}$. The measurement result of the gelatine from milkfish bone indicated not only a strong absorption in the number of waves of $1744.24 \mathrm{~cm}^{-1}$, which was a cluster of $\mathrm{C}=\mathrm{O}$ (aldehyde, carboxylic acid) but also weak uptakes in the number of waves of $1648.27 \mathrm{~cm}^{-1}$, which were a C-N cluster (amide) and $\mathrm{C}=$ $\mathrm{C}$ (aromatic ring). $\mathrm{C}=\mathrm{C}$ aromatic clusters were possibly derived from amino acids with aromatic side chains contained in the gelatine. Consequently, it concluded that the gelatine from milkfish bones contained a chain of the helix, the gelatine structure. The absorption area of amide II reached an absorption peak at 1541-1306 $\mathrm{cm}^{-1}$. The strong absorption line of the $1541.02 \mathrm{~cm}^{-1}$ wavelength was the $\mathrm{N}-\mathrm{H}$ bending wave of the secondary amide followed by absorption from the secondary $\mathrm{C}-\mathrm{N}$ amide strain at $1306.68 \mathrm{~cm}^{-1}$. The wave amide II was caused by the existence of bond deformations $-\mathrm{NH}$ - in protein. The measuring result of the milkfish bone gelatine indicated a strong absorption in the number of waves of $1465.29 \mathrm{~cm}^{-1}$, which was a group of $\mathrm{N}-\mathrm{H}$ (amide) and followed by strong uptake in the number of waves of $1384.30 \mathrm{~cm}^{-1}$, which was a C-H group (alkane). It proved that there was a deformation of $\mathrm{N}-\mathrm{H}$ bonds in the gelatine from milkfish bones to produce a chain of $\alpha$ helix. The specific absorption area of the last gelatine was amide III. The peak of the series was $1240-670 \mathrm{~cm}^{-1}$ and was associated with the triplehelix structure. The measurement result of the gelatine from milkfish bones indicated a weak absorption in the number of waves of 1245.20 and $1163.30 \mathrm{~cm}^{-1}$, which was a C-O cluster (alcohol, carboxylic acid). The C-O of the secondary alcohol absorbed in the number of waves of $723.37 \mathrm{~cm}^{-1}$ was $\mathrm{C}=\mathrm{C}-\mathrm{H}$ cluster as a result of powerful freeze then $\mathrm{H}$ outfield. Furthermore, the last freeze was on the number of waves of 508.35, which was
$-\mathrm{CH}=\mathrm{CH}_{2}$. It indicated that insufficient gelatine from milkfish bones contained a triple helix structure (collagen). From the results of the FT-IR spectra analysis above, the identified functional groups found in the sample were $-\mathrm{OH}, \mathrm{C}-\mathrm{O}, \mathrm{N}-\mathrm{H}, \mathrm{C}-\mathrm{H}, \mathrm{C}-\mathrm{N}$, and $\mathrm{C}=\mathrm{O}$ clusters, which were the essential functional group of gelatine.

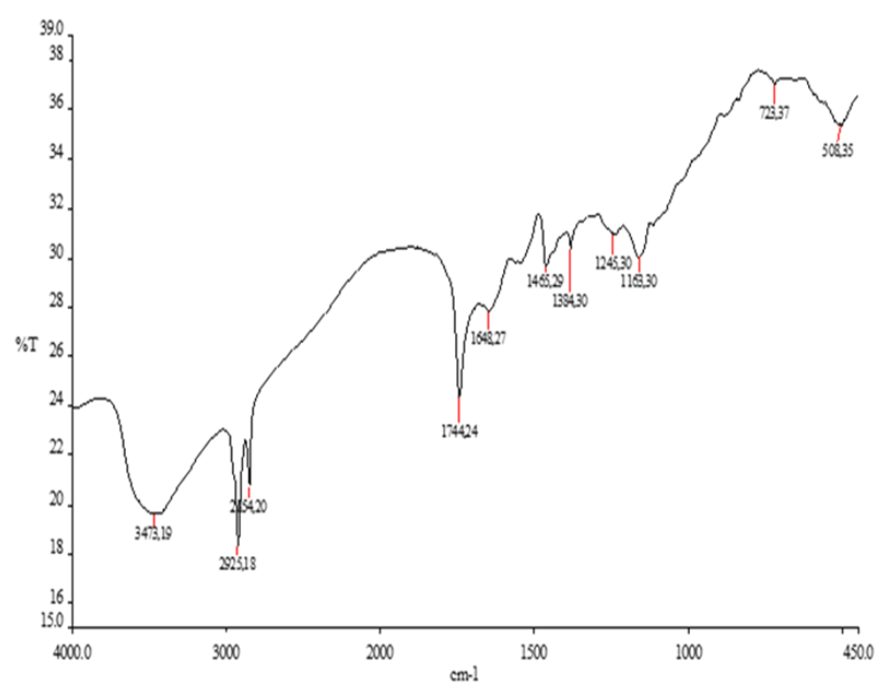

Figure 1. Functional group of gelatine from milkfish bones

\section{Conclusion}

The results of the study obtained that the best treatment was citric acid with a concentration of $9 \%$ resulting in a yield value at $10.48 \%$, gel strength at 283.1 g bloom, viscosity at $4.35 \mathrm{cP}$, melting point at $60.1^{\circ} \mathrm{C}$, and gelling point at $16.9^{\circ} \mathrm{C}$. From the results of the FTIR spectra analysis above, the identified functional groups found in the sample were $-\mathrm{OH}, \mathrm{C}-\mathrm{O}, \mathrm{N}-\mathrm{H}, \mathrm{C}-$ $\mathrm{H}, \mathrm{C}-\mathrm{N}, \mathrm{C}=\mathrm{O}$ clusters, which were the essential functional group of gelatine.

\section{References}

Ahmed, J., Ramaswamy, H.S. and Ngadi, M.O. (2005). Rheological Characteristics of Arabic Gum in Combination with Guar and Xanthan Gum Using Response Surface Methodology: Effect of Temperature and Concentration. International Journal of Food Properties, 8(2), 179-192. https:// doi.org/10.1081/JFP-200060234

Atma, Y. and Ramdhani, H. (2017). Gelatine extraction the indigenous pangasius catfish bone using pineapple liquid waste. Indonesian Journal of Biotechnology, 22(2), 86-91. https:// doi.org/10.22146/ijbiotech.32472

Balaji, W.K. and Tanaji, G.K. (2017). Effect of Various Acid on Physicochemical and Functional Characteristic of Gelatine from Swim Blader of Rohu (Labeo rohita). Journal of Food Science and Technology, 54(8), 2540 - 2550. https:// 
doi.org/10.1007/s13197-017-2699-0

Fernando, A.O., Elizabeth, B. and Ruben, B. (2007). Effect of Concentration, Bloom Degree and $\mathrm{pH}$ on Gelatine Melting and Gelling Temperatures Using Small Amplitude Oscillatory Rheology. International Journal of Food Properties, 10(4), 841 - 851. https://doi.org/10.1080/10942910601128895

Gelatin Manufacturers Institute of America. (2012). Gelatine Handbook. Massachusetts, USA: Gelatine Manufacturers Institute of America.

Gumilar, J. and Pramana, A. (2018). Production and Characterization of Halal Gelatine Made from Chicken Intestine. Journal of Agricultural Industry Technology, 28(1), 75-81. https://doi.org/10.24961/ j.tek.ind.pert.2018.28.1.75

Hidayat, G., Eko, N.D. and Laras, R. (2016). Characteristics of Nila bone Gelatine with Hydrolysis using phosphoric acid and Papain enzymes. Journal of Indonesian Fishery Product Processing, 19(1), 63-71. https://doi.org/10.17844/ jphpi.2016.19.1.69

Hijriani, P.R. (2018). Minapolitan Program on the development of Tambak fisheries in Sidoarjo Regency. E-Journal History Education, 6(1), 157165.

Huda, W.N., Windi, A. and Edhi, N. (2013). Study of physical and chemical characteristics Gelatine chicken Leg Bone Extract (Gallus-gallus bankiva) with the old variation of immersion and acid concentrations. Jurnal Teknosains Pangan, 2(3), 7075.

Jongjareonrak, A., Benjakul, S. and Visessanguan, W. (2005). Isolation and Characterisation of Acid and Pepsin-solubilised Collagens from The Skin of Brownstripe Red Snapper (Lutjanus Vitta). Food Chemistry, 93(3), 475-484. https://doi.org/10.1016/ j.foodchem.2004.10.026

Marion, K.M., Sussane, B. and Mette, K. (2010). Calcium from Salmon and Cod Bone is Well Absorbed in Young Healthy Men: A DoubleBlended Randomised Crossover Design. Nutrition and Metabolism, 7, 61. https://doi.org/10.1186/17437075-7-61

Nagai, T., Yamashita, E., Taniguchi, K., Kanamori, N. and Suzuki, N. (2001). Isolation and Characterization of Collagen from The Outer Skin Waste Material of Cuttlefish (Sepia lycidas). Food Chemistry, 72(4), 425-429. https://doi.org/10.1016/ S0308-8146(00)00249-1

Pertiwi, M., Atma, Y., Mustopa, A.Z. and Maisarah, Z. (2018). Physical and Chemical Characteristics of Gelatine from Pangasius Catfish Bone with Pre-
Treatment of Citric Acid. Journal of Food Technology Applications, 7(2), 83-91. https:// doi.org/10.17728/jatp.2470

Sadowska, M., Kolodziejska, I. and Niecikowska, C. (2003). Isolation of Collagen from the Skins of Baltic Cod (Gadus morhua). Food Chemistry, 81(2), 257-262. https://doi.org/10.1016/S0308-8146(02) 00420-X

Sompie, M., Rimbing, S.C. and Surtijono, S.E. (2014). Influence of acetic acid concentration and extraction temperature against the characteristics of pork skin Gelatine. Proceeding National Seminar of the Indonesian Chemical Association, 1(1),65-69.

Trilaksani, W., Mala, N. and Ima, H.S. (2012). Extraction of red snapper fish Gelatine (Lutjanus sp.) with an acid treatment process. Journal of Indonesian Fishery Product Processing, 15(3), 143149.

Zulkifli, M., Asri, S.N. and Nikmawati, S.Y. (2014). Low-yield, Gel point and a melting point of Tuna fishbone Gelatine processed with palm vinegar. Fisheries and Marine Scientific Journal, 2(2), 73-77. 